\title{
COMPARAÇÃO DO DESEMPENHO DA CITOPATOLOGIA CONVENCIONAL E CITOLOGIA EM MEIO LIQUIDO NA DETECÇÃO DE LESÕES: UMA REVISÃO SISTEMÁTICA
}

\author{
Lauana Aparecida SANTOS ${ }^{1}$ \\ Alessandra dos Santos Danziger SILVÉRIO ${ }^{2}$
}

Luisa Barbosa MESSORA ${ }^{3}$

\begin{abstract}
${ }^{1}$ Acadêmica, do Curso de Biomedicina, Universidade José do Rosário Vellano - UNIFENAS/Alfenas - MG. email: lauanexsantos@hotmail.com

${ }^{2}$ Farmacêutica, Docente do Curso de Biomedicina, Universidade José do Rosário Vellano - UNIFENAS/Alfenas - MG.

${ }^{3}$ Farmacêutica, Docente e Coordenadora do Curso de Biomedicina, Universidade José do Rosário Vellano UNIFENAS/Alfenas - MG.

Endereço para correspondência: e-mail: lauanexsantos@hotmail.com
\end{abstract}

Recebido em: 05/05/2014 - Aprovado em: 30/06/2014 - Disponibilizado em: 30/07/2014

RESUMO: A etiologia do câncer de colo do útero está diretamente associada à infecção pelo Papiloma Vírus Humano (HPV), sendo este de alto potencial oncogênico e causando infecções nos locais cutâneos e mucosos, levando ao aparecimento de diferentes tipos de verrugas. A infecção pelo HPV é considerada causa necessária, mas não o suficiente para o surgimento desta neoplasia. A citologia oncótica tem sido reconhecida, como importante e fundamental estratégia, pois é um método simples para o rastreamento de lesões, sendo possível o diagnóstico de doenças sexualmente transmissíveis (DST) e em especial o HPV. A citologia em meio liquido tem sido considerada, importante alternativa para o ganho de sensibilidade do exame citopatológico cérvico vaginal. Esta revisão concentra-se em comparar o desempenho da citologia em meio líquido com a citologia convencional na deteç̧ão de lesões cervicais. Destacando os problemas provenientes de coletas realizadas incorretamente, amostras mal acondicionadas e resultados falso negativos. Entretanto, a citologia em meio liquido, é uma técnica que pode minimizar estes problemas. Contudo, o seu custo elevado, estimula a busca por alternativas que torne a coleta ser viável à população.

Palavras chave: Câncer do colo do útero. Citodiagnóstico. Esfregaço vaginal. HPV. Neoplasias do colo do útero. Preventivo.

\section{PERFORMANCE COMPARISON OF CONVENTIONAL CYTOLOGY AND LIQUID BASED CYTOLOGY IN DETECTING LESIONS: A SYSTEMATIC REVIEW}

\begin{abstract}
ABSTRAT: Etiology of cancer of the cervix is directly associated with infection by Human Papilloma Virus (HPV), which is high oncogenic potential and causing infections in skin and mucosal sites, leading to the appearance of different warts. HPV infection is considered necessary cause, but not enough for the appearance of this neoplasm. The cytology has been recognized as an important and fundamental strategy, it is a simple method for tracking injuries, with possible diagnosis of sexually transmitted diseases (STDs), particularly HPV. The liquid based cytology has been considered an important alternative to the gain sensitivity of cervicovaginal Pap smear. The review focuses on comparing the performance of liquid-based cytology with conventional cytology for the detection of cervical lesions. Highlighting the problems come from collections made incorrectly, mishandled samples and false negative results are relevant. However, liquid based cytology is a technique that can minimize these problems. However, its high cost, stimulates the search for alternatives that make the collection to become viable population.
\end{abstract}

keywords: Cancer of the cervix . Cytodiagnosis. Vaginal smear. HPV. Cervical neoplasia. Preventive.

\section{Introdução}

As doenças crônico-degenerativas são mundialmente, causas de morbidade e mortalidade, dentre elas, destaca-se o câncer.

Este tem demonstrado elevadas taxas de óbitos. Na população feminina, destaca-se o câncer de colo do útero (CCU) sendo 
considerado de grande relevância epidemiológica por este motivo (FERNANDES et al., 2009).

A etiologia do CCU, segundo Fernandes et al., (2009) esta diretamente associada a infecção pelo Papiloma Vírus Humano (HPV), sendo este de elevado potencial oncogênico. Embora a infecção por este vírus seja considerada causa necessária, mas não o suficiente para o desenvolvimento de lesões neoplásicas. O câncer de colo do útero pode ter causas multifatoriais, a qualidade de vida da mulher pode ser um fator essencial para o desenvolvimento desta neoplasia.

O câncer de colo do útero $(\mathrm{CCU})$ é o segundo mais comum entre mulheres no mundo (MOORE, 2006), com cerca de 470 mil casos novos em todo o mundo (STERWART e KLEIHUES, 2003). Quase $80 \%$ desses casos ocorrem em países em desenvolvimento e em populações com piores condições socioeconômicas (BEHTASH e MEHRDAD, 2006). Segundo o Instituto Nacional do Câncer (INCA) no Brasil, as estimativas para o ano de 2012 serão válidas também para o ano de 2013 e apontam que surgiram 18 mil casos novos de câncer de colo do útero. No sexo feminino os cânceres mais incidentes são de pele não melanoma (71 mil casos novos), mama (53 mil), colo do útero, cólon e reto (16 mil) e pulmão (10 mil) (INCA, 2012).
A citologia cérvico-vaginal foi introduzida por George Papanicolau e Aureli Babes no ano de 1928 (MARTINS e REBALTA, 2005; KOSS e GOMPEL, 2006). A partir de 1943, com as pesquisas de Papanicolau e Traut, o método tornou-se o mais indicado para o rastreamento do $\mathrm{CCU}$ por ser um exame rápido e indolor, de fácil execução, realizado a coleta em nível ambulatorial, além de ser de baixo custo (MARTINS e REBALTA, 2005; CAPURRO et al., 2002).

Em uma busca para maior sensibilidade e especificidade para o método, novas técnicas de coleta e preparo do material foram desenvolvidas, em 1990 foi criada uma nova metodologia e introduziram a citologia em meio liquido (LBC). Para que a leitura das lâminas fosse realizada por computadores, era necessário que o esfregaço apresentasse o menor número possível de artefatos e sobreposições celulares. Desta maneira, surgiu a LBC para atender as demandas dos escrutínios (CAMPAGNOLI et al., 2005; ALVES et al., 2003; HOELUND, 2003).

A citologia em meio liquido é o resultado de intensos estudos sendo estes, mais de uma década de pesquisas, onde se buscou uma técnica, com condições de preparo citológico de excelência em fixação, preservação das células e de moléculas proteicas e ácidos nucléicos para a realização de estudos biomoleculares (VELASCO, 2001). 
Esta revisão de literatura tem o objetivo de comparar o desempenho da citopatologia convencional e citologia em meio liquido e discutir sobre as publicações relevantes sobre este tema.

\section{Métodos de coleta e preparação do material}

Para garantir uma amostra adequada, devem-se seguir algumas recomendações. Capurro et al., (2002) descreve que a paciente deve ser instruída para que não use duchas ou faça uso de lubrificantes vaginais, não estar no período menstrual e não ter relações sexuais 72 horas antes do exame. Basicamente, há duas formas de coletas utilizadas na citologia genital; a esfoliativa, que consiste na coleta de células que descamaram no fundo de saco da vagina, e abrasiva, que consiste na raspagem da mucosa epitelial genital (PLEWKA, 2007).

Os instrumentos utilizados na coleta cérvico-vaginal são: escova cilíndrica endocervical plástica ou de “nylon”, escova cônica e espátula de Ayre. Os métodos mais utilizados para a coleta consistem; na coleta convencional (dupla ou tripla) e coleta em meio liquido. Plewka, (2007) diz que a coleta dupla colhe-se material da endocérvice e ectocérvice, incluindo a junção escamo colunar (JEC). Na coleta tripla colhe-se o material da parede lateral superior da vagina ou fundo de saco vaginal, a ectocérvice incluindo a JEC e o canal endocervical, buscando uma maior representatividade celular de todo o trato genital feminino.

De acordo com as recomendações do Sistema de Bethesda (2001) e Nomenclatura Brasileira para laudos citopatológicos (2006), um esfregaço com mais de $75 \%$ de células escamosas (da ectocérvice) obscurecidas deve ser considerado insatisfatório para a interpretação, se não forem identificadas células anormais. Quando 50 a $75 \%$ das células escamosas estiverem obscurecidas, deverá ser descrito no laudo que a amostra é satisfatória para análise oncótica, porém parcialmente obscurecida, fornecendo informações sobre a qualidade do esfregaço ao profissional responsável pela coleta (SOLOMON, 2005).

Santos; Moreno e Pereira, (2009) investigaram a qualidade do exame de Papanicolau, os resultados demostraram que cento e doze esfregaços foram coletados e analisados. A análise constatou um número de amostras insatisfatórias acima do aceitável. A ausência de representatividade da junção escamo-colunar (JEC) foi à causa prevalente da classificação da amostra como insatisfatória. Os autores recomendam a revisão dos procedimentos de coleta e a repetição desta sempre que a JEC não estiver devidamente representada no esfregaço.

A identificação do material deve ser realizada no momento da coleta. Após, o material deve ser espalhado sobre a lâmina de 
modo regular, com boa espessura e rapidamente para evitar a dessecação e, consequentemente, preservar o estado morfológico das células e fixada imediatamente (FERNANDES et al., 2009). Em um estudo realizado por Américo et al., (2010) investigou-se a influência das formas de acondicionamento de lâminas de colpocitologia nos resultados dos laudos laboratoriais. Demostrando que dentre as laminas que foi acondicionado junto ao de outras voluntárias, e outro isoladamente, o acondicionamento, pode ter exercido alguma influência no laudo citológico do colo do útero. Houve discordância de 58,3\% em relação aos epitélios representativos da amostra e 48,2\% com relação às alterações celulares benignas. Sugerindo novos estudos sobre formas de acondicionamento de lâminas.

\subsection{Citologia em meio liquido ou base} liquida

A citologia em meio ou base liquida (CML) surgiu na década de 1990, para atender às demandas de escrutínio computadorizada. Para viabilizar a leitura das lâminas pelos computadores, eram necessários que os preparados apresentassem o menor número possível de artefatos e superposições de células, dessa maneira, os preparados citológicos em meio líquido foram chamados no início de citologia de mono camada ou camada fina (CAMPAGNOLI et al., 2005; HOELUND, 2003 e PAYNE et al., 2000).

A técnica em base liquida foi aprovada em 1996 pelo Food and Dry Administrations (FDA), dos Estados Unidos, para o seu uso em ginecologia e em outras especialidades médicas (CAMPAGNOLI et al., 2005).

$\mathrm{O}$ número de células em CML é considerado ideal, uma vez que ao ser acomodado no recipiente, a quase totalidade das células coletadas é transferida ao meio (PEREIRA et al., 2003). Essa técnica é realizada mediante a suspensão de células provenientes do material coletado em meio liquido fixador, teoricamente oferecem uma amostra mais representativa. Essa metodologia traz um grande avanço, uma vez que há evidencias de que $20 \%$ do material coletado pelo método convencional são transferidos à lâmina; o restante, que se encontra aderido aos instrumentos utilizados na colheita (escova/espátula) são descartados (DIAS et al., 2008).

As vantagens da CML é a presença de $100 \%$ do material coletado no liquido fixador, com a possibilidade de testes histoquímicos e de biologia molecular, para a identificação de agentes etiológicos como HPV. Segundo Tulio et al., (2007) o risco de câncer de colo do útero invasivo está diretamente relacionado á presença de HPV, com alto potencial oncogênico, a pesquisa destes tipos virais pelos métodos biomoleculares tem sido extremamente importante para o 
acompanhamento de mulheres que apresentam alterações citológicas. Segundo estudos realizados a maioria das infecções provocadas pelo HPV é transitória, aproximadamente, $70 \%$ delas desaparecem no período de um ano.

Em uma pesquisa realizada por Campos et al., (2005) a prevalência de HPV por meio da PCR em 41 mulheres portadoras do HIV e 38 mulheres soronegativas, foi encontrado prevalência de $73 \%$ no primeiro grupo e $24 \%$ no segundo. Em outra investigação, analisando resultados de PCR para o HPV de 208 mulheres infectadas pelo HIV, verificouse que, praticamente, todas eram soropositivas para o HPV (98\%), sendo que $80 \%$ delas eram infectadas por múltiplos genótipos e 90\% apresentavam citologia inflamatória (LEVI et al., 2004).

Dentre as vantagens, além de apresentar um menor número de resultados falsonegativo. Vários estudos mostraram que esse método apresenta um bom desempenho na detecção destes resultados. A preservação celular com melhora na qualidade da amostra facilita a leitura, reduz o tempo de duração dos exames em 30\%, e assim aumentado a produtividade do laboratório. Há também, evidente redução do número de hemácias, exsudato inflamatório, muco e preparo de lâminas sem precisar que a paciente seja convocada novamente (PEREIRA et al., 2003).
As desvantagens da CML são os altos custos dos equipamentos e manutenção dos mesmos, o treinamento do pessoal e profissional envolvido para a interpretação de um aspecto morfológico celular diferente da coleta convencional (CC), podendo gerar um maior número de esfregaços com atípias, as células atróficas e de metaplasia imatura podem ser confundidos ou mal interpretados com células atípicas (STABILE et al., 2012).

A repetição de exames cervico-vaginais em intervalos regulares, pelo método convencional ou em meio liquido, a realização de análise colposcopica imediata, exames de DNA do HPV para pesquisa de subtipos virais de alto risco, também a combinação de exames citológico cervical, são praticas utilizadas em vários países para o acompanhamento de mulheres com atipias em células escamosas de significado indeterminado (ASC -US) (TULIO et al., 2007). De modo geral, a maioria dos estudos realizados concorda que há um menor número de citologias insatisfatórias com a CML (STABILE et al., 2012).

\section{Metodologia}

Foi feita a busca de artigos científicos com os descritores "liquid-based cytology and conventional cytopathology" e comparação do desempenho da citologia em meio líquido e citologia convencional, sem restrição de data de publicação e idiomas. Após a busca, os artigos encontrados foram selecionados de 
acordo com o assunto proposto. Foram incluídas citações listadas nas referências dos artigos encontrados pela estratégia descrita.

\section{Discussão}

O exame citopatológico é o método mais difundido mundialmente para o rastreamento e investigação de lesões precursoras do câncer de colo do útero. A sua vulnerabilidade dos resultados a erros da coleta, preparação de lâminas e a subjetividade na interpretação dos resultados podem comprometer a sua sensibilidade e especificidade (STABILE et al., 2012). Novas técnicas têm sido desenvolvidas com o objetivo de melhorar a acurácia do exame citológico, destacando-se a citologia em meio liquido. A seguir serão relatadas publicações disponíveis na literatura que tratam da comparação entre os métodos de CC e CML.

Stabile et al., (2012) comparou as duas técnicas utilizadas na citologia oncótica, a CC e CML, em paciente com baixo risco para o câncer de colo do útero. Os resultados demostraram que a adequalidade dos esfregaços mostrou-se semelhante. A presença de elemento da JEC em 93\% das citologias convencionais e $84 \%$ das citologias em meio liquido, teve significância estatística, com relação à qualidade. Em diagnósticos de atípias, 3\% correspondem às citologias convencionais e em $10 \%$ as citologias em meio liquido, sendo elas em células escamosas de significado indeterminado. Ao compararem com a colposcopia com biopsia dirigida, o desempenho da CML foi superior, $66,7 \%$ de sensibilidade e $100 \%$ de especificidade.

Em alguns estudos, realizaram-se os dois tipos de coletas, mas em tempos diferentes, estes demonstraram que há um menor número de esfregaços insatisfatórios e maior representatividade da JEC na CML (KOSS e GOMPEL, 2006). Realizaram-se estudos em que as duas coletas também foram feitas, no entanto, simultaneamente com e sem diagnostico histológico, o desempenho dos dois métodos foi semelhante (LOGATTO et al., 2005; GIRIANELLI et al., 2004). Logatto et al., (2005) concluem que há maior sensibilidade pela CML e maior especificidade da CC.

Diaz e Kabawat, (1999) diz que as possíveis explicações para a maior sensibilidade da CML esta relacionada na melhora da coleta da amostra pelo intenso número de células que são liberadas no meio líquido. $\mathrm{Na} \mathrm{CML}$, ocorre uma diminuição de elementos obscuros, permitindo a detecção de células atípicas que, no esfregaço convencional poderiam não estar presentes. A preservação das células permite uma melhor categorização da amostra.

Em um estudo realizado, analisaram-se 174 esfregaços, comparando-se a CC e CML. Os resultados mostraram que houve $89,7 \%$ de concordância entre a CC e CML. Em 5,3\% dos casos considerados negativos na $\mathrm{CC}$ a CML foi positiva. Dentre as pacientes com 
resultados positivos, $52,7 \%$ foram positivas para a presença de HPV na PCR (CARMO, 2004).

Gerianelli et al., (2004) compararam a CC e CML, avaliando 1777 esfregaços de pacientes com idade entre 25 a 59 anos de idade. Os resultados observados com alteração foram de 9,6 \% para CC e 16,2\% para CML. Diferente do que ocorre no atendimento de rotina à mulher, a CML foi colhida após a CC, o que pode influenciar o percentual de exames insatisfatórios e o seu desempenho.

Ao analisar os resultados do estudo de Khalbuss et al., (2000) no qual realizou-se a comparação entre as duas técnicas, os resultados observados foram taxas de falso positivo de $28,4 \%$ para a citologia convencional e de $26,3 \%$ para a citologia em meio líquido. Também as taxas de falso negativo foram de $20 \%$ para a citologia convencional e de $17,6 \%$ parta a citologia em meio liquido, não mostrando diferença significativa entre os dois métodos.

Uma revisão sistemática, em 2008, avaliou 109 estudos, e a conclusão da investigação foi de que a CML apresentou um número menor de resultados insatisfatórios. A sensibilidade e especificidade não se observaram diferenças significativas (Dias et al., 2008).

Arbyn et al., (2008) realizou um estudo comparativo entre as duas metodologias discutidas e este verificou que dentre os estudos consultados também não revelou diferença estatística significativa na sensibilidade ou especifidade entre a CML e CC. Logatto et al., (2005) investigou 1095 esfregaços citológicos cervico-vaginais e este conclui que confirma a superioridade da citologia em base liquida.

Manrique et al., (2007) relata que o método de CML tem sido apontado como alternativa para superar a dificuldade de análise e intepretação do esfregaço preparado pela técnica convencional e desta forma, melhorar a adequalidade da amostra, diminui o número de esfregaços insatisfatórios e assim aumentando o número de diagnóstico de lesões de alto grau.

Pereira et al., (2003) conclui que os preparados em base liquida oferecem maior vantagem, pois a JEC esteve representada em $89 \%$ e $84 \%$ das amostras, enquanto a técnica convencional a representatividade foi de $22 \%$. Estudos demonstraram a importância da representação celular da junção escamo colunar.

\section{Considerações finais}

O papel da citologia e colposcopia no diagnóstico de lesões precursoras do câncer de colo do útero são de extrema relevância. Dessa forma, torna essencial enfatizar a importância da realização deste exame periodicamente.

As novas metodologias para tornar o exame mais sensível e especifico fica-nos a 
impressão de que os preparados em meio liquido oferecem maior qualidade $\mathrm{e}$ especifidade. Embora o esfregaço pela coleta convencional seja preconizado, daí surge à necessidade em tornar rotineiro os preparados em base liquida.

\section{Referencias}

ALVES, A.V. et al. Comparison of manual and automated methods of liquid-based cytologya: a morphologic study. Acta Cytologica. 2003; 48(2):187-93.

AMÉRICO, C.F.; CHAGAS, A.C.M.A.; LOPES, E.M.; DIAS, L.B.M.; LIMA, T.M.; MOURA, E.R.F.; PINHEIRO, A.K.B. Análise da influência do acondicionamento diferenciado de lâminas para colpocitologia no resultado laboratorial. Texto Contexto Enferm. 2010. 19(2): 343-50.

ARBYN, M.; BERGERON, C.; KLINKHAMER, P.; MARTIN-HIRSCH, P.; SIEBERS, A.G.; BULTEN, J. Liquid compared with conventional cervical cytology: a systematic review and metaanalysis. Obstet Gynecol. 2008;111(1):16777.

BEHTASH, N.; MEHRDAD, N. Cervical cancer: screening and prevention. Asian Pac J Cancer Prev. 2006; 7:683- 686.

CAMPAGNOLI, E.B.; SANDRIN, R.; BRAOSI, A.P.; LIMA, A.A.; FRANÇA, B.H.; MACHADO, M.A. Citologia em base líquida - uma nova opção para o diagnóstico de lesões bucais. Rev Bras Patol Oral. 2005;4:119-27.

CAMPOS, R.R.; MELO, V.H.; DEL CASTILHO, D.M.; NOGUEIRA, C.P.F. Prevalência do papillomavírus humano e seus genótipos em mulheres portadoras e nãoportadoras do vírus da imunodeficiência humana. Rev Bras Ginecol Obstet. 2005;27(5):248-56.
CAPURRO, I.V.; ROJO, J.A.E. et al. Programa de deteccion y control de cancer de cuello uterino en servicio de salud araucania sur. Rev Chil de Obstet y Ginecol. 2002. 67(2). CARMO, B.B. Estudo comparativo entre a citologia convencional e a citologia em meio líquido na detecção de lesões escamosas intraepiteliais e invasoras do colo uterino associadas à infecção pelo Papiloma Vírus Humano. [Tese] Belo Horizonte, Faculdade da Farmácia da UFMG; 2004.

DIAS, E.P.; MILAGRES, A.; SANTOS, J.B.; VALLADARES, C.P.; SOUZA, A.C.B.; PINHEIRO, R.S. Estudo comparativo de raspados orais submetidos à técnica de citologia em meio líquido e citopatologia convencional. J Bras Patol Med Lab. 2008;44(1):25-29.

DIAZ, R.L.; KABAWAT, S. Performance of a fluid-based, thin-layer Papanicolaou smear method in the clinical setting of a independent laboratory and an 105 outpatient screening population in New England. Arch. Pathol. Lab. Med. 1999;123:817-821.

FERNADES, J.V.; RODRIGUES, S.H.L.; COSTA, Y.G.A.S.; SILVA, L.C.M.; BRITO, A.M.L.; AZEVEDO, J.W.V.;

NASCIMENTO, E.D.; AZEVEDO, P.P.M.; FERNANDES, T.A.A.M. Conhecimentos, atitudes e prática do exame de Papanicolaou por mulheres, Nordeste do Brasil. Rev Saúde Pública 2009;43(5):851-8.

GIRIANELLI, V.R.; THULER, L.C.; SZKLO, M.; DONATO, A.; ZARDO, L.M.; LOZANA, J.A. et al. Comparação do desempenho do teste de captura híbrida II para HPV, citologia em meio líquido e citologia convencional na detecção precoce do câncer do colo do útero e de suas lesões precursoras no Rio de Janeiro, Brasil. Rev Bras Cancerol. 2004;50(3):225-6.

HOELUND, B. Implementation of liquidbased cytology in the screening programme against cervical cancer in the County of Funen, Denmark and status for the first year. Cytopathology, v. 14, n. 5, p. 269-74, 2003. 
Instituto Nacional do Câncer (INCA).

Estimativa para 2012 do Câncer do colo

uterino no Brasil e diferentes regiões

[Internet]. [Acessado em 2013

fevereiro10;Disponível

em:http://www.inca.gov.br/conteudo_view.as

$\mathrm{p}$ ?id=1793].

KHALBUSS, W.E.; RUDOMINA, D.;

KAUFF, N.D. et al. SpinThin, a simple, inexpensive technique for preparation of thinlayer cervical cytology from liquid-based specimens. Cancer. 2000; 90: 135-42.

KOSS, L.G.; GOMPEL, C. Citopatologia ginecológica com correlações histológicas e clinicas. São Paulo: Roca; 2006.

LEVI, J.E.; FERNANDES, S.; TATENO, A.F.; MOTTA, E.; LIMA, L.P.; ELUF-NETO J. et al. Presence of multiple human papillomavirus types in cervical samples from HIV-infected women. Gynecol Oncol. 2004;92(1):225-31.

LONGATTO, F.A.; PEREIRA, S.M.; DI LORETO, C.; UTAGAWA, M.L.; MAKABE, S.; MAEDA, M.Y. et al. DCS liquid-based system is more effective than conventional smears to diagnosis of cervical lesions: Study in high-risk population with biopsy-based confirmation. Gynecol Oncol. 2005;97(2):497-500.

MANRIQUE, E.J.C.; TAVARES, S.B.N.; SOUZA, N.L.A.; ALBURQUERQUE, Z.B.P.; ZEFERNO, L.C.; AMARAL, R.G. A revisão rápida de $100 \%$ é eficiente na detecção de resultados falsos-negativos dos exames citopatológicos cervicais e varia com a adequabilidade da amostra: uma experiência no Brasil. Rev Bras Ginecol Obstet. 2007; 29(8):408-13.

MARTINS, N.V.; RIBALTA, J.C. Patologia do trato genital inferior. São Paulo: Roca; 2005.

MOORE, D.H. Cervical cancer. Obstet Gynecol. 2006; 107:1152-1161.
Nomenclatura Brasileira para Laudos Cervicais e Condutas Preconizadas Recomendações para Profissionais de Saúde. Rev Bras Ginecol Obstet. 2006;28(8):486504.

PAYNE, N. et al. Liquid-based cytology for cervical screening. Cytopahology, v. 11, p. 469-70, 2000.

PEREIRA, S.M.; UTAGAWA, M.L.; PITTOLI, J.E.; AGUIAR, L.S.; MAEDA, M.Y.; LONGATTO, F.A. et al. Avaliação da celularidade citológica em preparados de base líquida. Rev Inst Adolfo Lutz. 2003;62(1):359.

PLEWKA, J. Estudo sobre variações no método de citologia em meio líquido para o exame de Papanicolaou. [Tese], Curitiba, Universidade Federal do Paraná; 2007. SANTOS, M.L.; MORENO, M.S.; PEREIRA, V.M. Exame de Papanicolaou: Qualidade do esfregaço realizado por alunos de enfermagem. Rev Bras.

Canc.2009;55(1):19-25.

SOLOMON, D.; NAYAR, R. Sistema Bethesda para citopatologia cervicovaginal. 2 ed. Rio de Janeiro: Revinter; 2005.

STABILE, S.A.B.; EVANGELISTA, D.H.R.; TALAMONTE, V.H.; LIPPI, U.G.; LOPES, R.G.C. Estudo comparativo dos resultados obtidos pela citologia oncótica cérvicovaginal convencional e pela citologia em meio líquido. Einstein. 2012;10(4):466-72.

STEWART, B.W.; KLEIHUES, P. World cancer report. In: Stewart BW, Kleihues P, editors. Cancers for the female reproductive tract. Lyon: IARC Press; 2003. p. 215-218.

TULIO, S.; PEREIRA, L.A.; NEVES, F.B.; PINTO, A.P. Relação entre a carga viral de HPV oncogênico determinada pelo método de captura híbrida e o diagnóstico citológico de lesões de alto grau. J Bras Patol Med Lab. 2007; v. 43 n. 1 p. 31-35. 